\title{
An Alternative View of Small Firm Adaptation
}

\author{
Colin Jones
}

School of Management

University of Tasmania

Private Bag 16

Sandy Bay

Tasmania 7005

Australia

Phone: +61 (0) 362262826

Fax: +61 (0) 362262808

Email: Colin.Jones@utas.edu.au 


\title{
An Alternative View of Small Firm Adaptation
}

\begin{abstract}
Increasingly, small firms with a history tied to a specific geographic location are having their survival threatened by new and innovative web-based entrants. This paper considers the plight of such firms and proposes an alternative means to reflect on how they may or may not learn about such threats or opportunities. Adopting an evolutionary perspective, the construct absorptive capacity is used to highlight the deficiencies of current market orientation theory to explain the process of firm learning. The conceptual model of evolutionary potential provides a framework through which both the firm and its owner/s' abilities to learn can be taken into account.
\end{abstract}

Keywords: Small Firms, Market Orientation, Absorptive Capacity, and Evolutionary Theory

\section{Introduction}

This paper considers the process of adaptation by small place-based firms operating in webimpacted environments, i.e. firms whose operations have historically been determined by and confined to a specific geographical location and, environments characterized by new innovative entrants who use the web's technologies to provide unprecedented and unique consumer value (Jones \& Hecker, 2003a). In this context, small refers to those firms with typically less than twenty employees in either product or service markets. In an environment characterised by change, a firm's survival is dependent upon the ability to adapt to the 
changing environment. The alternative, to be replaced by other firms whose routines and competencies achieve a better fit with the operating environment.

In the spirit of the growing calls to consider the context, process and (probable) outcomes associated with a firm's entrepreneurial efforts (Aldrich \& Martinez, 2001) to adapt, this paper aims to achieve the following. First, to consider the context of the change brought about by the Internet's World Wide Web (the web). Second, the shortcomings of using market orientation theory as a traditional explanation small firm adaptation is discussed. Third, through the introduction of evolutionary perspectives to consider the nature of small firm learning, the construct absorptive capacity is considered as an alternative lens through which to view the process of small firm learning. Fourth, a conceptual model of evolutionary potential is proposed to build a framework through which the context, process and probable outcomes of such learning can be reconciled. Finally, the proposed model is again contrasted to market orientation theory to emphasis the need to more fully appreciate the process of small firm learning.

\section{The Web}

Although the history of the Internet dates back to its conception in 1957 as a source of United States defence force communications, approval for commercial use in 1991 heralded the availability of a technology (the web) with seemingly unlimited application. During the next six years, accepted interface designs (e.g. Gopher, Mosaic, Netscape, and Explorer) aided the widespread adoption of the web as a communication and exchange medium. While the disruptive influence of the web has varied across industries, it has nevertheless been an unalterable environmental force. As the business landscape alters, the fitness of the small 
place-based firm is dependent upon the ability to find solutions to problems introduced into the operating environment by technological change.

The web has grown at an unprecedented scale and speed with many firms caught off guard finding it increasingly difficult to incorporate it into their operations (Aldrich, 1999). Aldrich and Baker (2001) note that the web’s development has thus far been reliant upon a core technology, that being the web browser (e.g. Microsoft Explorer). The browsers act as a dominant design that facilitates awareness of entrepreneurial opportunities. However, it is at a peripheral technical subsystem level (Murmann \& Tushman, 2001) that much confusion remains and prevents exploitation of the web. Initially, there was much optimism that the web’s exploitation by firms would be based upon an appreciation of consumer needs and wants (e.g. Hoffman \& Novak, 1997; Lodish, Morgan \& Kallianpur, 2001). Market-oriented firms (see Narver \& Slater, 1990; Jaworski \& Kohli, 1993), armed with intimate knowledge of consumer needs and wants would develop new routines and competencies to satisfy the changing needs of consumers, thus enabling adaptation to the changing environment.

However, as Connor (1999) and Wrenn (1997) note, where radical technologies significantly alter market conditions, the ability of consumers to articulate their latent needs is very questionable. Not surprisingly, little evidence presently exists to support this prescriptive view of small firm exploitation of the web. Conversely, growing evidence suggests many small firms in advanced economies have experienced difficulties exploiting the web (Vescovi, 2000; Chaston, Badger, Mangles \& Sadler-Smith, 2001; Plume, 2001; Van Beveren \& Thomson, 2002; Jones, Hecker \& Holland, 2003). This is hardly surprising given the unique marketplace interactions specific to each firm, its customers, employees and suppliers through 
which the web's interactive technologies must diffuse. Within this fast changing business landscape, a race exists between entrepreneurs who employ a heuristic-based logic (Alvarez \& Busenitz, 2001) to simplify environmental uncertainty and the Darwinian process of natural selection acting upon any firm whose routines lose favour. Clearly, it remains unclear whether or not traditional theories such as market orientation provide a satisfactory explanation of the process of firm learning within the context of such social change.

\section{Market Orientation: An Illusion of Knowledge?}

A market orientation is defined as; 1) the systematic gathering of information on customers and competitors, both present and potential; 2) the systematic gathering analysis of the information for the purposes of developing market knowledge and; 3) the systematic use of such knowledge to guide strategy recognition, understanding, creation, selection, implementation, and modification (Hunt \& Morgan, 1995, p. 11). The application of traditional marketing theory to explain the process of firm learning and adaptation to changing conditions is largely taken for granted (e.g. Slater \& Narver, 1995; Slater \& Narver, 1998). However, this paper proposes that market orientation theory is beset with unresolved problems (Jones \& Hecker, 2003b) that prevent its use as a lens through which to consider small firm learning in web-impacted environments. The argument to be made is that it is not feasible to use market orientation theory to consider a firm's evolutionary potential, or, its ability to sense and respond to environmental shocks through the acquisition and exploitation of specific external knowledge.

Despite the jewel in the crown status afforded market orientation by marketing theorists, conceptualization and subsequent measurement issues have continually attracted the attention 
of sceptics (e.g. Gable, 1995; Wrenn, 1997; Henderson, 1998; Caruana, 1999; Gauzente, 1999; Jones et al., 2003). Debate continues as to what constitutes a market orientation, how is it best measured and ultimately, what is its influence? For researchers of small firms, the use of market orientation theory to further understand the evolution of firm routines and competencies would seem an invitation to further scepticism. Despite assertions of the applicability of market orientation theory to small firms (Pelham \& Wilson, 1996), the findings of Jones et al., (2003) cast added concern over the theory’s place in relatively simple operating structures.

The case-based qualitative and quantitative method used by Jones et al., (2003) exposed a distinct lack of strategic development and use of market knowledge to exploit the web. The firms appeared confused between anticipated behaviors and actual behaviors when completing the Pelham and Wilson (1996) market orientation questionnaire. The recorded high degrees of market orientation for both marketplace and marketspace undoubtedly did not accurately reflect a true comparison of the firm's abilities to acquire and use market knowledge across both domains. Clearly an issue of what popular market orientation instruments actually measure must be resolved to remove the illusion that knowledge exists from which conclusions can be drawn.

Further, it is also argued (Min, Song \& Keebler, 2002) that the validity of the market orientation theory as developed in the non-web context, does not explicitly consider the nature of information transmission within web-impacted environments. Previously, a market orientation was considered necessary and largely sufficient to ensure optimal firm learning (Slater \& Narver, 1995). However, recently Slater (2001) states that a market orientation 
while necessary for learning is not sufficient to support the sense and respond behaviors critical to firm adaptation in dynamic and turbulent markets. The implications being that higher-order (generative) learning processes and not traditional market oriented behaviours are perhaps better predictors of firm learning. That higher-order learning is an outcome of market orientation, separate to, or an inclusive process through which firms convert information into the knowledge that guide's strategy development is not resolved by the extant literature (e.g. Slater \& Narver, 1995; Slater \& Narver, 1998). With reference to organizational learning and market orientation, Baker and Sinkula (2002, p. 8) cast market orientation as a separate construct that "reflects the quantity of a firm's market information processing activities and the weight that these activities have on the strategic planning process. It does not reflect the quality of a firm's market information processing activity”. This view is consistent with assertions that the presence of a market orientation alone will not guarantee higher-order learning processes through which optimal learning outcomes are achieved (Dickson 1996; Jaworski \& Kohli 1993). As such, predicting the value and influence of a market orientation may be difficult, if not impossible, without separating the nonoverlapping properties of the two constructs (Cook \& Campbell, 1979).

In short, market orientation theory does little to explain the speed, direction, and intensity of the firm's search for external knowledge. It doesn’t differentiate between the information sought (and received) that complements the firm’s existing knowledge base, and information that is foreign to the firm's knowledge base. It ignores the importance of the firm's absorptive capacity (Cohen and Levinthal 1990) thereby overlooking the importance of prior knowledge to assist recognition of new information. The web is likely to represent a novel domain with exploitation dependent upon the broadening of existing knowledge bases. Ultimately, the 
application of traditional market orientation theory within the context discussed appears problematic. The remainder of the paper thus attempts to contribute an alternative view, one that accommodates the context, process, and (probable) outcomes (Aldrich \& Martinez, 2001) associated with small firm learning within web-impacted environments.

\section{The Nature of Small Firm Learning}

There are two prominent schools of thought on organizational learning (Aldrich, 1999), the adaptive learning perspective and the knowledge development perspective. These two approaches provide insights into the difficulties faced by many small place-based firms. The first approach employs experiential learning and is common practice within small firms (Carson \& Gilmore, 2000). Basically, successful behaviours are repeated and unsuccessful behaviours discarded. The potential downside of such a learning process in uncertain markets is the reinforcement of the known at the expense (and ignorance) of the unknown (Cohen \& Levinthal, 1990). The second approach relies upon creativity and experimentation and is not directly dependent on prior experience and therefore perhaps more suitable for dealing with technological change. It is this second type of behaviour that is typically demonstrated by entrepreneurs. However, while effective entrepreneurs are considered to be exceptional learners (Smilor, 1997), the distribution of effective (or innovative) entrepreneurs in any given population of firms is typically low. Aldrich and Kenworthy (1999) note that

overwhelmingly new firms are created through imitation rather than innovation. With reference to the various works of Donald Campbell, they observe the tendency of most individuals to conform to social pressures rather than disobey such pressures through experimentation, creativity and other challenging behaviours. 
Clearly, it should not be taken for granted that all small firm owners have the same capacity to interpret the change and uncertainty associated with web-impacted environments. However, learning must occur in order to maintain (or increase) the fitness of the firm's routines. While it is likely that small firms will conduct many different forms and combinations of learning, what matters most is the development and maintenance of a fit between the firm's routines and the operating environment. The firm has a stock of working knowledge that represents its history, routines, competencies, and market positioning. Davenport and Prusak define a firm's working knowledge as "a fluid mix of framed experience, values, contextual information, and expert insight that provides a framework for incorporating new experiences and information. It originates and is applied in the minds of knowers. In organizations, it often becomes embedded not only in documents or repositories but also in organizational routines, processes, practices, and norms” (1998, p. 5).

This definition suggests that knowledge simultaneously resides not only within individuals but also the firm and its activities. As such, small firm learning is seen as an interactive process occurring across entities (e.g. individuals, routines, firms, populations of firms, and ecosystems) that is governed by specific events (e.g. start-up and adaptation) and subsumed within the evolutionary processes of variation, selection and retention (VSR). In this context, evolutionary theory "studies the creation of new organizational structures (variation), the way in which entrepreneurs modify their organizations and use resources to survive in changing environments (adaptation), the circumstances under which such organizational arrangements lead to success and survival (selection), and the way in which successful arrangements tend to be imitated and perpetuated by other entrepreneurs (retention)” (Aldrich \& Martinez, 2001, p. 42). 
The above discussion highlights the inseparability of the small firm owner's disposition to learning from that of the small firm's ability to learn. As will be further discussed, a central thesis of this article is that the pressure of natural selection upon the firm's routines equally reflects the selection pressure on the owner's "habits of thought” (Veblen, 1925, p. 191). As such, through attention to the firm's routines (and sub-routines) that support the firm's learning capabilities, the probable consequences of such habits emerge. Ultimately, for the small place-based firm embedded in a web-impacted environment, it is through selection of the fittest (and most adaptive) temperaments that new enterprise activities emerge as favoured variations. At opposing ends of a continuum, habits representing indifference and curiosity are proposed to best illustrate the small place-based firm's approach to learning within webimpacted environments. Each end point is tethered by competing evolutionary positions. Indifference leads to the preservation of the status quo and therefore little active consideration of new external knowledge. Whereas, a tendency towards curiosity leads to an increased awareness of, and alternative ways of thinking about marketplace variations, a necessary precondition of adaptive evolution (Pfeffer, 1982). However, as will be discussed latter, it is through maintaining a shifting balance between the two end points that optimal learning is most likely achieved.

It is proposed that the construct absorptive capacity when viewed from an evolutionary perspective can advance this discussion. In their recent review of the absorptive capacity literature, Zahra and George reconceptualized absorptive capacity as "a set of organizational routines and processes by which firms acquire, assimilate, transform, and exploit knowledge to produce a dynamic organizational capability” (2002, p. 186). Using this perspective, 
absorptive capacity enables the probable consequences of learning (or not learning) to be considered from within the workings of the proposed neo-Darwinian-Lamarckian model of evolutionary potential. When considered from an evolutionary point of view, absorptive capacity theory highlights critical activities that would greatly influence small place-based firm adaptation in web-impacted environments. Absorptive capacity theory identifies knowledge development capabilities (and deficiencies) similar to the generic evolutionary processes "of variation, selection, retention and struggle that jointly produce patterned changing in evolving systems” (Aldrich, 1999, p. 2).

Since the seminal contribution of Cohen and Levinthal (1990), absorptive capacity has been associated with the acquisition and use of knowledge to enhance firm performance through increased learning and innovation (e.g. Keller, 1996; Liu \& White, 1997; Kim, 1998). Absorptive capacity, as defined by Zahra and George (2002) has four dimensions, the acquisition, assimilation, transformation and exploitation of knowledge. These four dimensions allow observation of specific firm capabilities that would typically influence the potential adaptation of a firm. Two subsets, potential absorptive capacity and realized absorptive capacity, host the four dimensions. Potential absorptive capacity (i.e. acquisition and assimilation) is the capability to sense what information is relevant, acquire it, analysis it, comprehend it and internalise it. As such, it accounts for the first necessary condition of evolutionary potential, appreciation of the exogenous environmental forces that may or may not favour the firm's existing routines. Realized absorptive capacity relates to the routines that blend existing knowledge with newly acquired knowledge to gain new insights to opportunities or problems and provide structured pathways to develop new competencies (i.e. transformation and exploitation). Thus the second necessary condition of evolutionary 
potential is satisfied through the adaptive ability of the firm's routines via internal selection processes.

In summary, the reconceptualization of absorptive capacity by Zahra and George has elevated the construct from a single factor component to one containing two distinct components (i.e. Potential and realized absorptive capacity) that provide the foundation of "a dynamic capability pertaining to knowledge creation and utilization” (2002, p. 185). It is argued that the development of a plausible explanation of small place-based firm learning in webimpacted environments is critical given that "learning is a key process that distinguishes technological innovation as a game of chance from one that is a game that involves skill as well” (Garud, Nayyar \& Shapira, 1997, p. 7). That is, without learning the evolutionary prospects of the small place-based firm are determined predominately by macro forces.

\section{A Conceptual Model of Evolutionary Potential}

If firms can indeed sense and respond to environmental change, what degree of response is appropriate and how can we ensure replication of the most favoured routines? The conceptual model of evolutionary potential provides the framework in which the small firms learning processes can be considered. To facilitate this discussion, the model's architecture is explained. First, the importance of including both neo-Darwinian and Lamarckian evolutionary perspectives within the model is explained. Then the major components of the model are outlined and their proposed relationships discussed. These components include the owner's disposition, routines, the evolutionary process of VSR and the influence of absorptive capacity as the mechanism that potentially provides the firm with a dynamic capability. It should be noted that it is not the nature of small place-based firms that motivates 
the models development, but rather the context of the social setting within which they increasingly operate.

Economic evolution has traditionally been viewed as Lamarckian evolution given the acceptance of "both the inheritance of acquired characteristics and the timely appearances of variation under the stimulus of adversity” (Nelson \& Winter, 1982, p. 11), with only metaphoric references made Darwinian evolution (Knudsen, 2001). That is, variation is a function of the firm's response to the changing environment (i.e. adaptation). In contrast, biotic evolution is considered Darwinian in nature with survival of the fittest through the process of natural selection due to environmental forces. That is, environmental forces select random variations. However, Knudsen (2001) and Hodgson (2003) both argue that through viewing Lamarckian or Darwinian explanations as mutually exclusive, the social scientist can only reach an incomplete explanation of the evolutionary change. The argument being that nesting Lamarckian evolution within an overarching neo-Darwinian framework provides essential guidance for the adaptive process of Lamarckian evolution. Thus, the evolutionary potential of a firm is determined not solely through recognition of the need and ability to change, but more so through the ability to increase the fitness of their routines vis-à-vis the operating environment. Put simply, while Lamarckian evolution is capable of transforming the firm's goals, boundaries and activities (Aldrich, 1999) through internal selection mechanisms, ultimately it is neo-Darwinian selection forces acting upon the complex of routines that make up the firm, that matter most.

In the biotic sense, evolution is determined by the ongoing process of genotypes (i.e. genes) determining the structure of phenotypes (i.e. organisms) that interact, replicate and whose 
subsequent form is constantly subject to the process of natural selection (Hodgson, 2001). The process of genetic variation is random and therefore not Lamarckian. However, from an economic perspective, routines (Nelson \& Winter, 1982; Knudsen, 2003) and/or habits (Hodgson, 2001) are akin to genotypes, with the firm (and its owner/s) representative of the phenotype. Variation is introduced as a result of the firm's interaction (e.g. experience and learning) within the operating environment. Consequently, within the small place-based firm, the units of selection are the sub-routines that are analogous to the owner's character and learning abilities, and the operating routines that represent the firm's activities. Within the model of evolutionary potential illustrated in Figure I, a baseline (Knudsen, 2003) exists to regulate the degree and success of Lamarckian modification of routines, thereby providing a guidance mechanism.

\section{Take in Figure I}

While incorporating both operating and search routines (Nelson \& Winter, 1982), the model also incorporates both active and inactive search routines, cast as sub-routines. Nelson and Winter state that operating routines can be considered as those routines that are relatively stable and determine short-run behaviour. Within the model, changes to operating routines are observed across the firm's goals, boundaries and activities. In contrast, search routines (i.e. sub-routines) provide the basis for the process of Lamarckian evolution through which operating routines are altered. Search routines are enacted through the evolutionary process of VSR and have the potential to provide the firm with a dynamic capability. A dynamic capability being defined as the firm's “ability to integrate, build, and reconfigure internal and external competences to address rapidly changing environments” (Teece, Pisano, \& Shuen, 
1997, p. 516). Consistent with Zahra and George (2002) and Zott (2003), search routines may potentially be a dynamic capability when knowledge created and utilized by the search routines provides the basis for maintaining the fitness of the firm's operating routines.

The model also accounts for the possibility that a focus on internal efficiencies and/or compliance to social norms may result in existing operating routines dominating the presence and scope of search routines. The stability of the operating routines may override the desire to explore alternative variations that might otherwise increase (or decrease) the future fitness of the firm's operating routines. Under such circumstances, Lamarckian evolution is stymied through the reliance upon past selection criteria with search routines largely inactive. Such a scenario in web-impacted environments would see the firm's evolutionary potential diminished and the potential threat of neo-Darwinian forces increased. Thus, if the firm is unable to respond appropriately to the stimuli present within its changing operating environment, its medium to long-term survival is doubtful (Langlois, 1997). Given that adaptation is dependent upon new enterprise, the presence of core rigidities (Leonard-Barton, 1992) or simple ignorance may ensure retention of obsolete operating routines, thus reducing the evolutionary potential of the firm.

The firm's degree of absorptive capacity (i.e. its learning ability) is subsumed within and intertwined with the evolutionary processes of VSR. Therefore, within the model of evolutionary potential, a firm’s dynamic capability is a function of the degree of absorptive capacity. The four dimensions of absorptive capacity (acquisition, assimilation, transformation, and exploitation) provide the necessary ingredients for Lamarckian evolution. However, the presence of potential absorptive capacity does not predicate the ability to 
successfully transform and exploit knowledge (Zahra \& George, 2002). Therefore, while the firm's search routines begin the process of acquisition and assimilation of external knowledge (i.e. the introduction of variation), the selection of new (or retention of old) operating routines that maintain or increase fitness are dependent upon sub-routines that facilitate the transformation and exploitation of external knowledge. From this perspective, the firm's evolutionary potential is dependent on the complementary relationship between potential and realized absorptive capacity that are mediated by the extent to which the firm's sub-routines support all four dimensions.

The last component of the model is the disposition of the owner. While it is unlikely that any owner is either only indifferent or only curious about change in the operating environment, the model serves to illustrate the learning outcomes of both dominant dispositions. The discussion follows this path to emphasis sub-optimal learning processes that restrict evolutionary potential. Through recognizing the shortcomings of both learning processes, a clearer notion of what processes would support optimal learning in web-impacted environments becomes more evident. Just "as a dark background is required for exhibiting the brightness of a picture” (James, 1880, p. 442), so do sub-optimal learning processes highlight the learning processes that increase evolutionary potential. However, a paradox regarding the necessity of both indifference and curiosity exists, one that ultimately determines the firm's evolutionary potential. It is proposed that optimal learning processes are a function of the owner/s (and therefore the firm's) ability to maintain a shifting balance between both indifference and curiosity to facilitate the evolutionary process of VSR. 
Regardless of whether the owner's habits of thought result in a disposition towards indifference or curiosity; they nevertheless introduce degrees of efficiency that significantly influence the process of learning. At either end of the continuum, stable habits engender efficiency (Postrel \& Rumelt, 1996) into the owner's day-to-day activities. However, the blocking out effect of such efficiency creates two potentially disastrous learning pathways for the small place-based firm. Habitual indifference to learning about the changing operating

environment $\left(S^{2}\right)$ will most likely result in the retention of existing routines without consideration of their future suitability. Under such conditions, it is the exploitation of existing operating routines that dominate. Alternatively, habitual curiosity $\left(\mathrm{S}^{1}\right)$ may have the opposite effect, with firms extremely efficient at acquiring information relating to other possible means of production, but unable to determine how best produce their goods or services. The importance of the owner's disposition, and the issue of efficiency are demonstrated through further consideration of exactly what information is sought and how it is applied.

\section{The Misplaced Optimism of Market Orientation Theory}

While the proposed model of evolution potential cannot claim to be prescriptive like market orientation theory, it is however ground in context, process, and consideration of probable outcomes. The context of the business landscape within which increasing numbers of small place-based firms operate is difficult to accommodate within market orientation research. It is not the flow of information between the firm and its stakeholders that matters. It is the nature (i.e. origin and compatibility) of the information and the ability of the firm (and therefore, its owner/s) to acquire it, comprehend it, and exploit it that matters most. With market orientation theory, the actual owner's disposition to learning is unknown. It is conceivable 
that respondents completing market orientation surveys may be inclined to retain existing structures, or be forever curious about new ways of producing their goods and services.

What is missing is an acute appreciation of the process of learning that occurs within individual firms. Without observing that the necessary balance between VSR is occurring, there is little point in concluding that any firm has the ability to sense and positively respond to environmental change. Through the combination of absorptive capacity and evolutionary theory, an understanding of both the context and process related to small firm learning is possible. Through thinking about three learning scenarios, identified as $S^{1}, S^{2}$, and $S^{3}$ on Figure I, this point is illustrated.

At $S^{1}$, the phenotype (i.e. the firm's operating routines, boundaries, and goals) remains largely unaltered through ignorance of marketplace variations. At $S^{2}$ the phenotype is subject to optimistic, but ill-conceived change. However, at $S^{3}$ the entire evolutionary process represents a learning process through which the small place-based acts with consideration of what is internally possible balanced against what is desirable externally. Realized absorptive capacity is possible through the firm's ability to complement existing knowledge by introducing and integrating relevant external knowledge. Therefore, the firm's sub-routines that ensure awareness and comprehension of marketplace variations would also support the exploitation of marketplace opportunities to ensure the firm's survival. Only at $S^{3}$ do the generic evolutionary processes of VSR work in harmony to enable Lamarckian change to occur with due consideration to the neo-Darwinian process of natural selection. Given the propensity of many small firm owners to work in and not on the business (Gerber, 1995), it is plausible that 
the learning behaviours associated with positions $S^{1}$ and $S^{2}$ may be more dominant than those attached to $S^{3}$.

To use an adaptation of Aristotle's approach to the use of anger, any firm can change - that is easy. But to change the right routines, to the right degree, at the right time, for the right purpose, and in the right way - that is not easy. Essentially, the presence of an organisational learning capability must exist to ensure the successful acquisition, assimilation, transformation, and exploitation of specific external knowledge. At present, market orientation theory and its received view does not allow the researchers to fully understand the context and processes associated with small place-based firm learning in web-impacted environments.

\section{Conclusion}

This discussion contributes to the field of entrepreneurship by examining the learning processes through which market opportunities are discovered and subsequently exploited, a critical issue in entrepreneurship theory (Alvarez \& Barney, 2002). A unique research opportunity exists to observe specific web-impacted industries dominated by small placebased firms (e.g. book retailers and travel agencies) and determine how firms obtain and use external knowledge to gain or improve the resources under their control. This opportunity arises because the web has grown at an unprecedented scale and speed with many of the firms caught off guard finding it increasingly difficult to incorporate it into their operations (Aldrich, 1999). Given that “future evolution cannot be positively anticipated” (Witt, 2002, p. 17), a plausible research aim is confirmation that adaptation within web-impacted environments is very limited with the learning processes suggested at $S^{1}$ and $S^{2}$. Such an 
approach aims to test the hypothesis that the evolutionary potential of small place-based firms is a product of their abilities to sense and respond to environmental shocks through the acquisition and exploitation of specific external knowledge.

\section{References}

Aldrich, H.E. (1999), Organizations evolving, Sage Publications, London.

Aldrich, H.E. and Baker, T. (2001), "Learning and legitimacy: Entrepreneurial responses to constraints on the emergence of new populations and organizations", in Schoonhoven, C.B. and Romanelli, E. (eds), The entrepreneurship dynamic: Origins of entrepreneurship and the evolution of industries, Stanford University Press, California, pp. 207-235.

Aldrich, H.E. and Kenworthy, A.L. (1999), "The accidental entrepreneur - Campellian antinomies and organizational foundings”, in Baum, J.A.C. and McKelvey, B. (eds), Variations in organization science: In honor of Donald T. Campbell, Sage Publications, London, pp. 19-34.

Aldrich, H.E. and Martinez, M.A. (2001), "Many are called, but few are chosen - An evolutionary perspective of the study of entrepreneurship", Entrepreneurship Theory and Practice, Vol. 25 No. 4, pp. 41-56.

Alvarez, S.A and Barney, J.B. (2002), "Resource-based theory and the entrepreneurial firm" in Hitt, M.A., Ireland, R.D., Camp, S.D. and Sexton, D.L. (eds), Strategic entrepreneurship: Creating a new mindset, Blackwell Publishing, Cornwall, pp. 89-105.

Alvarez, S.A. and Busenitz, L.W. (2001), “The entrepreneurship of resource-based theory”, Journal of Management, Vol. 27, pp. 755-775.

Baker, W.E. and Sinkula, J.M. (2002), "Market orientation, learning orientation and product orientation - Delving into the organization's black box”, Journal of Market-Focused Management, Vol. 5 No. 1, pp. 5-23.

Carson, D. and Gilmore, A. (2000), "Marketing at the interface - Not what but how", Journal of Marketing Theory and Practice, Vol. 8 No. 2, pp. 1-7.

Caruana, A. (1999), "An assessment of the dimensions and the stability of items in the MARKOR scale”, Marketing Intelligence \& Planning, Vol. 17 No. 5, pp. 248-253.

Chaston, I., Badger, B., Mangles, T. and Sadler-Smith, E. (2001), "The Internet and ecommerce - An opportunity to examine organisational learning in progress in small manufacturing firms”, International Small Business Journal, Vol. 19 No. 2, pp. 134-147. 
Cohen, W.M. and Levinthal, D.A. (1990), “Absorptive capacity: A new perspective on learning and innovation’, Administrative Science Quarterly, Vol. 35, pp. 128-152.

Connor, T. (1999), "Customer-led and market-oriented: A matter of balance”, Strategic Management Journal, Vol. 20 No. 12, pp. 1157-1163.

Cook, T.D. and Campbell, D.T. (1979), Quasi-experimentation: Design \& analysis issues for field settings, Rand McNally College Publishing Company, Chicago.

Davenport, T.H. and Prusak, L. (1998), Working knowledge: How organizations manage what they know, Harvard Business School Press, Boston, MA.

Dickson, P.R. (1996), "The static and dynamic mechanics of competition: A comment on Hunt and Morgan's comparative advantage theory”, Journal of Marketing, Vol. 60, October, pp.102-106.

Gable, T.G. (1995), "Market orientation: Theoretical and methodological concerns”, in Stern, B.B. and Zinkham, G.M. (eds) Proceedings of the American Marketing Association Summer Educators’ Conference, American Marketing Association, Chicago, pp. 368-375.

Garud, R., Nayyar, P.R. and Shapira, Z.B. (1997), Technological innovation: Oversights and foresights, Cambridge University Press, Melbourne.

Gauzente, C. (1999), “Comparing market orientation scales: A content analysis”, Marketing Bulletin, Vol. 10, pp. 76-82.

Gerber, M.E. (1995), The e myth revisited: Why most small business don't work and what to do about it, HarperCollins Publishers, New York.

Henderson, S. (1998), "No such thing as market orientation: A call for no more papers", Management Decision, Vol. 36, pp. 598-609.

Hodgson, G.M. (2001), "Is social evolution Lamarckian or Darwinian”, in Laurent, J. and Nightingale, J. (eds), Darwinism and evolutionary economics, Edward Elgar, Cheltenham, UK, pp. 87-120.

Hodgson, G.E. (2003), “The mystery of the routine: The Darwinian destiny of an evolutionary theory of economic change”, Revue Économique, Vol. 54 No. 2, pp. 355-384.

Hoffman, D.L. and Novak, T.P. (1997), "A new marketing paradigm for electronic commerce”, The Information Society, Vol. 13 No. 1, pp. 43-55.

Hunt, S.H. and Morgan, R.M. (1995), “The comparative advantage theory of competition”, Journal of Marketing, Vol. 59, April, pp. 1-15.

James, W. (1880), “Great men, great thoughts, and the environment', The Atlantic Monthly, Vol. 46, pp. 441-459. 
Jaworski, B.J. and Kohli, A.K. (1993), "Market orientation: Antecedents and consequences”, Journal of Marketing, Vol. 57 No. 3, pp. 53-71.

Jones, C., Hecker, R. and Holland, P. (2003), "Small firm Internet adoption: Opportunities forgone, a journey not begun”, Journal of Small Business and Enterprise Development, Vol. 10 No. 3, pp. 287-297.

Jones, C. and Hecker, R. (2003a), “Invisible opportunities and irreversible trends”, Journal of New Business Ideas \& Trends, Vol. 1 No. 1, pp. 38-49.

Jones, C. and Hecker, R. (2003b), "Market orientation: See no evil, speak no evil, hear no evil”, Proceedings of the $5^{\text {th }}$ World Marketing Congress, Curtin University, Perth, June 11-14.

Keller, W. (1996), “Absorptive capacity: On the creation and acquisition of technology in development”, Journal of Developmental Economics, Vol. 49 No. 1, pp. 199-210.

Kim, L. (1998), "Crisis construction and organizational learning: Capability learning in catching-up at Hyundai Motor”, Organization Science, Vol. 9 No. 4, pp. 506-521.

Knudsen, T. (2001), "Nesting Lamarckism with Darwinian explanations: Necessity in economics and possibility in biology", in Laurent, J. and Nightingale, J. (eds), Darwinism and evolutionary economics, Edward Elgar Publishing, Cheltenham, UK, pp. 121-159.

Knudsen, T. (2003), “Economic selection theory”, Journal of Evolutionary Economics, Vol. 12 No. 4, pp. 443-470.

Langlois, R.N. (1997), "Cognition and capabilities: Opportunities seized and missed in the history of the computer industry”, in R. Garud, R., Nayyar, P. and Shapira, Z. (eds), Technological innovation, Cambridge University Press, New York, pp. 71-94.

Leonard-Barton, D. (1992), "Core capabilities and core rigidities: A paradox in managing new product development”, Strategic Management Journal, Vol. 13 No. 5, pp. 111-125.

Lodish, L.M., Morgan. H.L. and Kallianpur, A. (2001), Entrepreneurial marketing, John Wiley \& Sons, New York.

Liu, X. and White, R.S. (1997), "The relative contributions of foreign technology and domestic inputs to innovation in Chinese manufacturing industries”, Technovation, Vol.17 No. 3, pp. 119-125.

Min, S., Song, S. and Keebler, J.S. (2002), “An Internet-mediated market orientation (IMO): building a theory”, Journal of Marketing Theory and Practice, Vol. 10 No. 2, pp. 1-11.

Murmann, J.P. and Tushman, M.L. (2001), "From the technology cycle to the entrepreneurship dynamic: The social context of entrepreneurial innovation", in Schoonhoven, C.B. and Romanelli, E. (eds), The entrepreneurship dynamic: Origins of 
entrepreneurship and the evolution of industries, Stanford University Press, California, pp. 178-203.

Nelson, R.R. and Winter, S.G. (1982), An evolutionary theory of economic change, Harvard University Press, Cambridge.

Narver, J.C. and Slater, S.F. (1990), "The effect of market orientation on business profitability”, Journal of Marketing, Vol. 54, October, pp. 20-35.

Pelham, A.M. and Wilson, D. (1996), “A longitudinal study of the impact of market structure, and market orientation culture on dimensions of small-firm performance", Journal of the Academy of Marketing Science, Vol. 24 No. 1, pp. 27-43.

Pfeffer, J. (1982), Organizations and organization theory, Pitman, Melbourne.

Plume, H. (2001), "Survival of the e-Fittest”, http://www.capcollege.bc.ca/admin/Formedia/2001releases/ebiz.html, Accessed on 5/8/2001.

Postrel, S. and Rumelt, R.P. (1996), "Incentives, routines and self-command", in Dosi, G. and Malerba, F. (eds), Organization and strategy in the evolution of the enterprise, MacMillan Press, London, pp. 72-102.

Slater. S.F. (2001), "Market orientation at the beginning of a new millennium”, Managing Service Quality, Vol. 11 No.4, pp. 230-232.

Slater, S.F. and Narver, J.C. (1995), “Market orientation and the learning organization”, Journal of Marketing, Vol. 58, July, pp. 63-74.

Slater, S.F. and Narver, J.C. (1998), "Customer-led and market-oriented: Lets not confuse the two”, Strategic Management Journal, Vol. 19 No. 10, pp. 1001-1006.

Smilor, R.W. (1997), "Entrepreneurship: Reflections on a subversive activity”, Journal of Business Venturing, Vol. 12, pp. 341-346.

Teece, D.J., Pisano, G. and Shuen, A. (1997), "Dynamic capabilities and strategic management”, Strategic Management Journal, Vol. 18 No. 7, pp. 509-533.

Van Beveren, J. and Thomson, H. (2002), "The use of electronic commerce by SMEs in Victoria, Australia”, Journal of Small business Management, Vol. 40 No. 3, pp. 250-253.

Veblen, T. (1925), The theory of the leisure class, George Allen \& Unwin, London.

Vescovi, T. (2000), "Internet communication: The Italian SME case", Corporate Communications - An International Journal, Vol. 5 No. 2, pp. 107-111.

Witt, U. (2002), “How evolutionary is Schumpeter's theory of economic development”, Industry and Innovation, Vol. 9 No. 1/2, pp. 7-22. 
Wrenn, B. (1997), “The market orientation construct: Measurement and scaling issues”, Journal of Marketing Theory and Practice, Vol. 5 No. 3, pp. 31-54.

Zahra, S.A. and George, G. (2002), “Absorptive Capacity: A review, reconceptualization, and extension”, Academy of Management Review, Vol. 27 No. 2, pp. 185-203.

Zott, C. (2003), "Dynamic capabilities and the emergence on intraindustry differential firm performance: Insights from a simulation study”, Strategic Management Journal, Vol. 24 No. 2, pp. 97-125. 
Figure I : A Model of Evolutionary Potential

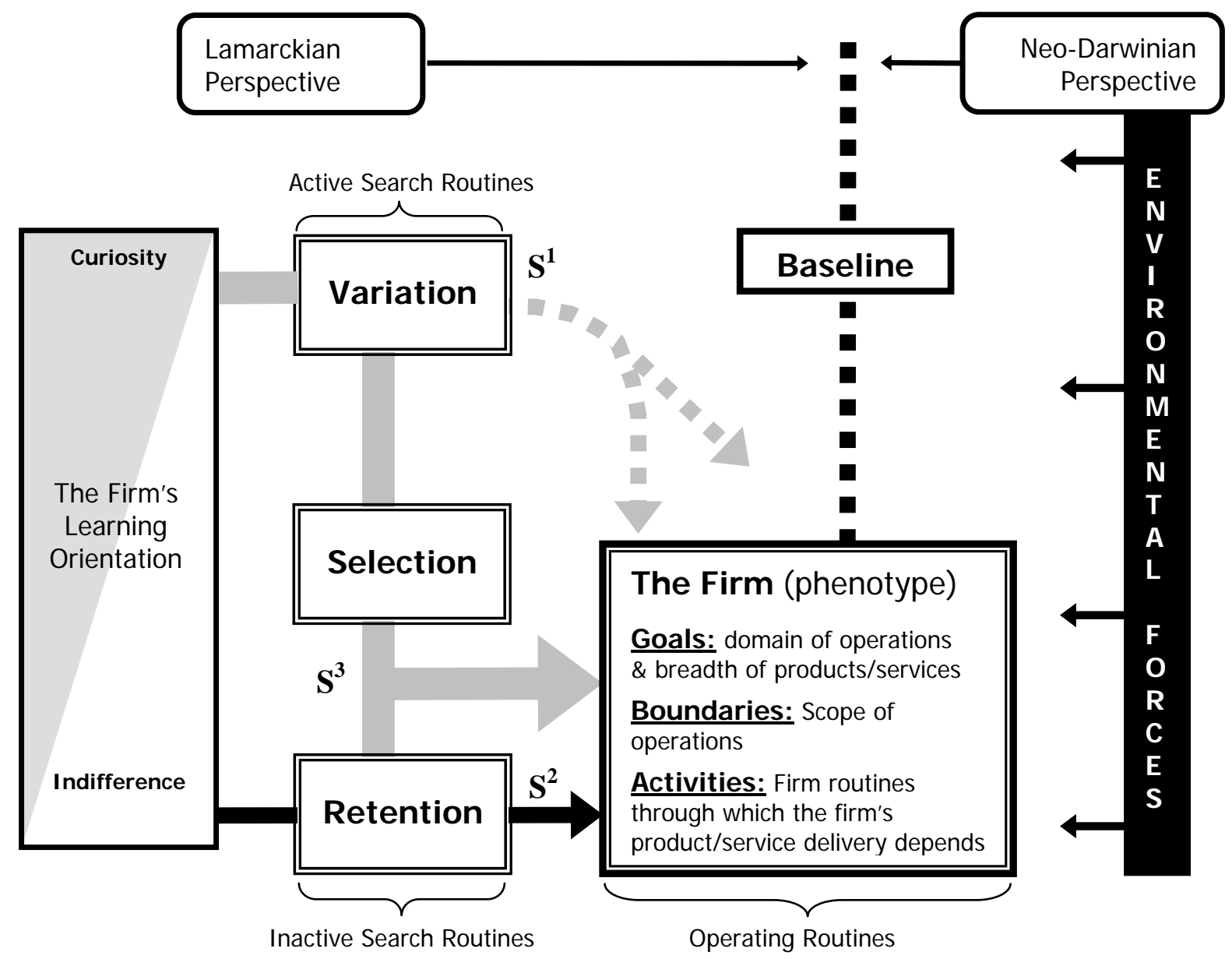

